\title{
1. Introduction and overview: the purposes and operations of the IMF
}

\subsection{INTRODUCTION}

The International Monetary Fund (IMF or 'the Fund') is the world's premier international financial institution. In 2015 it had a total of 188 member countries spanning all geographical regions of the world and all levels of economic development from the richest economies to the poorest. For many years after it was established in 1946 it was not the subject of widespread academic study. Isolated studies certainly existed covering various aspects of the Fund's operations, but there was not a large or comprehensive research literature to which reference could be made.

This paucity of academic research did not prevent people from having firmly held views about the institution. The views were diverse and frequently diametrically opposed. Those on the political 'right' saw the Fund as bailing out countries that had been seriously mismanaged by providing them with relatively 'soft' low cost financial assistance. To these critics, the IMF often caused more problems that it cured by sustaining such regimes and postponing necessary economic reform. In contrast, those on the political 'left' saw it as imposing austerity measures on vulnerable countries and as having a negative impact on economic growth and development. They perceived the Fund as an institution dominated by advanced countries and as representing their political and commercial interests usually to the detriment of poorer countries.

Lively as the debate about the IMF was, it tended to be polemic in style and grounded in ideology rather than analysis. Claims and counter claims were made with, at best, only passing reference to empirical evidence. When evidence was cited, it was usually partial, selective and anecdotal.

The contemporary situation is different. Polemics still features in debates about the IMF, but there is now a substantial scientific literature upon which to draw. This later research has attempted to analyse the Fund's role and operations both theoretically and empirically.

In this book we aim to contribute to the contemporary debate about the IMF by offering empirically based analyses of the Fund's operations. To do this we draw together some of our previously published work 
on various aspects of the IMF's activities but we also present new and previously unpublished material.

\subsection{THE PURPOSES AND EVOLUTION OF THE IMF}

The IMF was conceived at the Bretton Woods conference in 1944 as part of a global response to the Great Depression of the 1930s. The basic idea was to set up an international financial institution that would help avoid the beggar thy neighbor policies that had characterized that period. The Fund was seen as providing short to medium term finance to member countries facing balance of payments difficulties, in order to allow them to pursue policies of economic adjustment that did not rely on competitive devaluation and protectionist trade policies. In the words of the IMF's Articles of Agreement, a central purpose was to make the resources of the IMF available to members under 'adequate safeguards' and to provide them with the opportunity to 'correct maladjustments in their balance of payments without resorting to measures destructive of national or international prosperity.'

In principle, the rationale for the Fund's existence was to offset elements of 'market failure'. These included information failures, externalities and contagion, coordination failures, financing gaps, and the inability of market operators to produce the 'public good' of conditionality or to provide an international lender of last resort that would supply adequate international liquidity in the event of crises. In the years during which the Fund has existed, opinions have varied as to how important these elements of market failure are, and therefore how important the IMF is. At times when markets have seemed to be working adequately, the need for the IMF has been questioned. When markets have more conspicuously failed the importance of the IMF has been highlighted.

During the Bretton Woods era there were few challenges to the IMF's existence. After all, the Fund had been designed to manage that system. But with the system's demise in 1973 some observers argued that it had outlived its usefulness. In the immediate post Bretton Woods era, economic adjustment was supposed to rely more heavily on the flexible exchange rates adopted by the world's largest and wealthiest economies. Private international capital markets (particularly in the context of petro dollar recycling) were seen as providing balance of payments finance and, as a result of these developments, there was a reduced need for the increased international reserves that might otherwise have been created by allocations of the IMF's newly introduced Special Drawing Rights. In addition, in the late 1970s, there was a move away from multilateralism in international monetary relations, as the European Monetary System was 
set up in 1979. Much of the initial rationale for the IMF seemed to have disappeared, and indeed for the next 30 years the IMF's traditional lending concentration on its higher-income members evaporated, to be replaced by agreements with low and middle-income countries. Indeed, at the beginning of the 1980s, all the IMF's programs were with low-income countries (LICs) that tended not to have access to international capital markets.

Things then changed. The overvalued US dollar suggested that freely operating foreign exchange markets did not necessarily guarantee that equilibrium rates would be generated. Furthermore, the debt crisis in the developing world suggested that private international capital markets could be susceptible to periods of both over-lending and under-lending. Relatively large Latin American economies became clients of the Fund and the IMF took on the role of trying to help resolve the debt crisis. In the global conditions of the 1980s the IMF rapidly re-acquired international relevance and prominence. Over this time period its portfolio of agreements settled into a pattern that comprised low-income countries (often on a fairly prolonged or frequent basis) and, more infrequently, emerging economies in circumstances where they had lost access to international capital markets.

The Fund's comeback continued during the early 1990s as it was confronted with the challenge of assisting countries that had embarked on a transition from centrally planned to market-based economic systems. Then, in the later 1990s it was faced with the East Asian financial crisis. In the latter case, a debate ensued between the Fund's supporters who argued that the crisis reinforced its underlying raison d'etre, and detractors who argued that it had helped to cause the crisis by offering a financial safety net that had in turn encouraged private capital markets to underestimate risk. The latter arguments found expression in the claim that IMF lending involved a severe moral hazard; a claim that was emphasized strongly in the Meltzer Commission report (Meltzer, 2000). Critics also argued that the design of programs in East Asia was inappropriate, involving excessive conditionality and much more emphasis on compressing domestic demand through fiscal austerity than was required (see, for instance, Stiglitz, 2002). Between these two poles of disaffection, the Fund played a prominent (though still controversial) role in the debt forgiveness initiatives that emerged at the turn of the millennium.

Following the trials and tribulations at the end of the 1990s and beginning of the 2000s the world economy became relatively benign for many countries that had previously used IMF resources. The absence of significant international financial volatility fostered further debate about whether the IMF was needed any longer. There was an increasing groundswell of opinion amongst influential financial journalists and a number of well-respected central bank officials (including the Governor of the Bank of England) that the Fund was becoming less and less relevant. The 
reduction in the Fund's lending activity was not simply because of an exogenous decline in the number of countries seeking its help, but also because it seemed to be rather ineffective in exercising preventative multilateral surveillance (Bird and Willett, 2007).

The lower profile of the IMF in the middle of the 2000s is reflected by Table 1.1 which shows the decline in both the number of IMF arrangements and in the total amount of IMF lending. However, obituaries of the Fund proved to be premature. The global financial and economic crisis that erupted in 2008 enhanced the Fund's profile and increased its relevance both in terms of its systemic purpose and its bilateral function in assisting individual member countries that had been particularly adversely affected by the crisis. There was a sharp increase in IMF lending. The Eurozone crisis in the late 2000s saw Greece, Portugal and Ireland negotiating programs with the IMF, the first time that high-income countries had sought IMF assistance since the mid-1970s.

Not surprisingly, the pattern of IMF activity, and the waxing and waning of its prominence, corresponds closely with major international financial events. Although an important part of the Fund's functions can reasonably be seen as seeking to avoid and avert crises, the reality has been that its role as an international financial trouble-shooter has been most prominent when severe economic distress has been faced by relatively large individual economies or by the world economy as a whole (see Bird, 1999). On top of this the IMF has experienced its own existential issues irrespective of global financial crises.

In this book we take the basic rationale for the IMF as given. Even at times when the world economy is enjoying a period of relative tranquility it remains vulnerable to economic and financial shocks and instability and, in these circumstances, the IMF fulfils a useful function. Societies opt not to close down fire services just because there has been a period when no major fires have occurred. Nor do they completely disband air and sea rescue services immediately after weather conditions improve. Rather than deliberating as to whether the world needs the IMF, we are keen to examine key elements of its bilateral dealings with member countries under the auspices of its stabilization and adjustment programs.

\subsection{THE LAYOUT OF THE BOOK}

\subsubsection{IMF Quotas}

Many of the IMF's activities are based, albeit often quite loosely, on countries' quotas. The Fund has sometimes referred to quotas as the institution's 


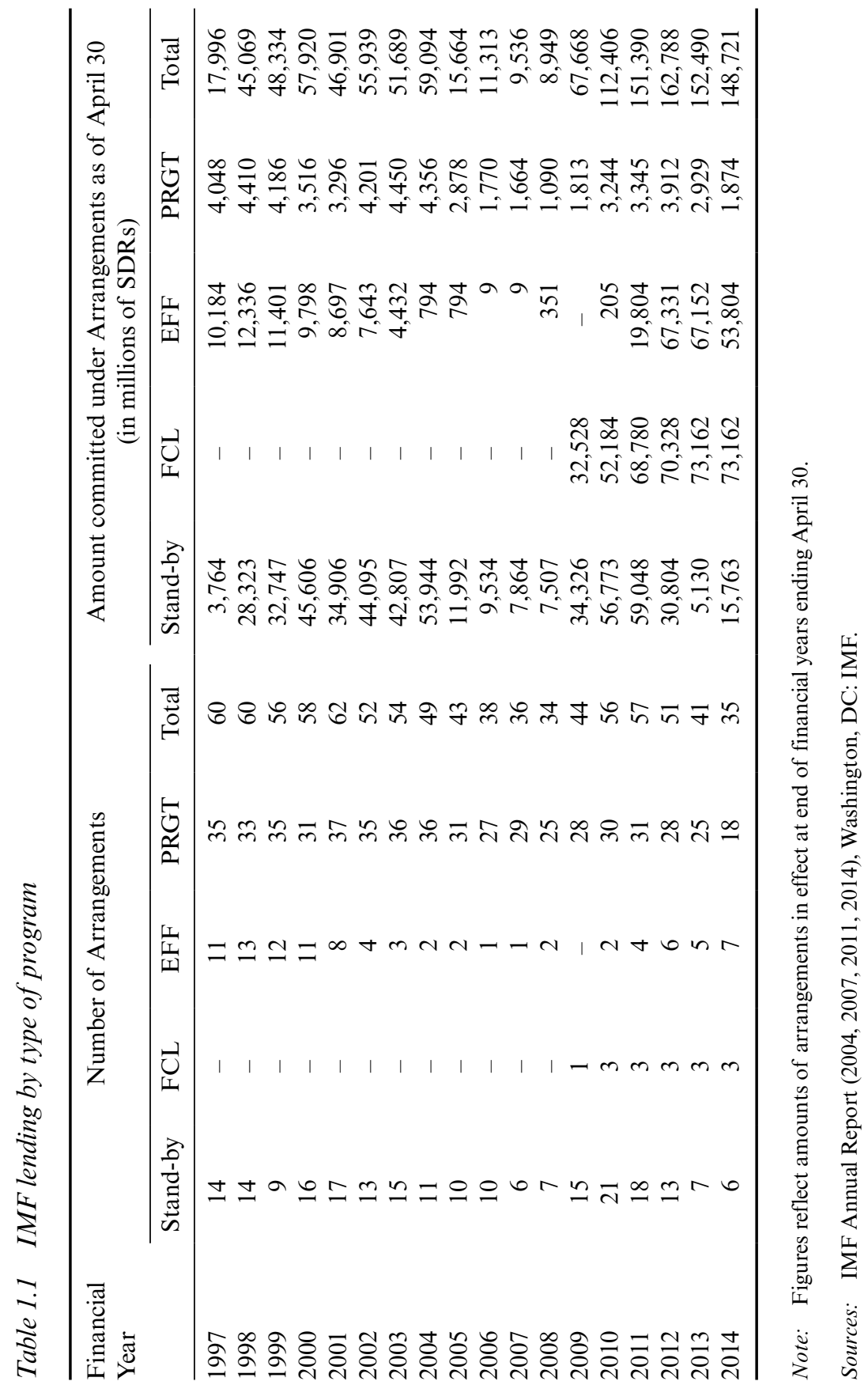


'building blocks'. It is therefore important to investigate whether they form an appropriate foundation for determining the way in which the Fund is financed and the way in which it allocates its resources to member countries. Quotas also have important implications for the balance of power within the institution since they help determine the distribution of voting rights and therefore affect decision-making. In Chapter 2 (previously published as Bird and Rowlands, 2006) we examine various aspects of IMF quotas and argue that an underlying problem with them is that one common formula has been used to help determine different dimensions of the Fund's activities (voting, subscriptions and drawing rights). These dimensions of the IMF's operations are likely to be at odds with one another. However, pointing to the problems associated with quotas has turned out to be much easier than formulating agreed modifications that overcome them. The reform of IMF quotas has proved to be an ongoing challenge.

\subsubsection{The Range of IMF Lending Facilities}

Another organizational issue relates to the number and nature of the IMF's lending windows. Table 1.1 gives an indication of the range of facilities available. Over the years facilities have been extended, abandoned or modified. It is therefore interesting to explore whether the facilities have fulfilled distinct or overlapping functions. In Chapter 3 (previously published as Bird and Rowlands, 2007b) we compare lending under the non-concessional and concessional facilities. We also investigate whether there are discernible differences in the use of the IMF's principal non-concessional facilities, stand-by agreements and Extended Fund Facility (EFF) credits.

We discover that in the years following the introduction of the EFF in 1974 there were significant differences in the economic circumstances in which the two non-concessional facilities were used. But we also find that these differences diminished over time; by the early 2000s they no longer existed. This result suggests that either the IMF's lending facilities have not always been used appropriately and for the purposes for which they were designed, or that a degree of redundancy has sometimes been allowed to persist. It also suggests that from time to time there may be unused potential for reforming the design of individual lending facilities. In this regard it is interesting to observe that there was a spate of reform to the design of lending facilities in the aftermath of the global economic crisis at the end of the 2000s; although the Fund opted to retain the EFF alongside its more frequently used stand-by facility.

The policy challenge facing the Fund is to ensure that its contemporary portfolio of lending windows allows it to cope with the particular and potentially diverse circumstances under which countries turn to it for 


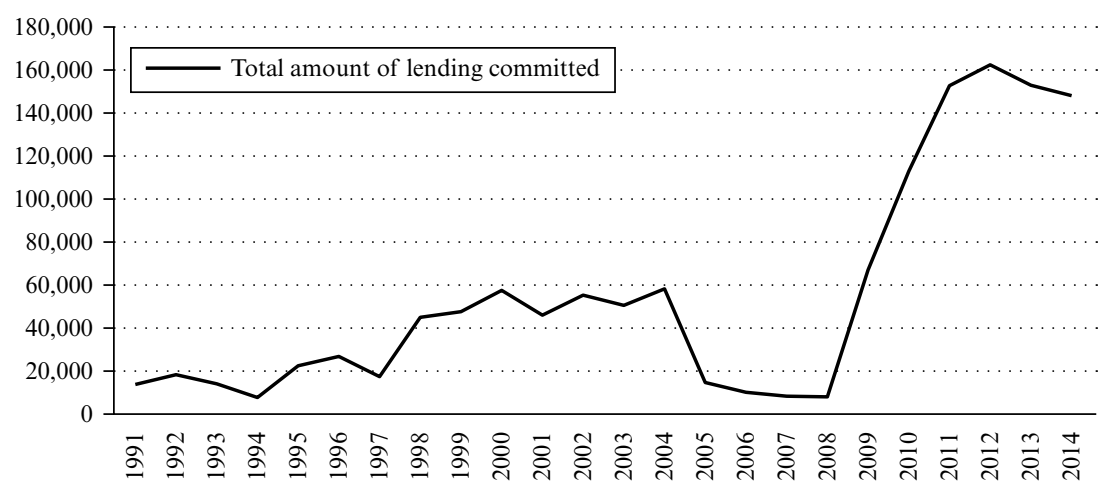

Note: Figures reflect amount of arrangements in effect at end of financial years ending April 30.

Source: IMF Annual Report (2000, 2004, 2011, 2014), Washington, DC: IMF.

Figure 1.1 Total amount of IMF lending (in millions of SDRs)

assistance (Bird, 2003). In designing individual IMF lending facilities it is therefore important to understand the factors that influence participation in IMF programs. Chapters 4 and 5 address this issue.

\subsubsection{Participation in IMF Programs}

In Chapter 4 (previously published as Bird and Rowlands, 2010) we turn to the temporal pattern of aggregate IMF lending that is reflected in Figure 1.1 and Table 1.1. In principle, the aggregate demand for IMF resources may be influenced by the size and distribution of current account balance of payments deficits, the size and distribution of holdings of international reserves, access to private international capital markets, levels of external debt and the cost of borrowing from the IMF comprising both the rate of charge on IMF credit, and perhaps more significantly, the perceived cost in terms of the conditionality associated with IMF programs.

In Chapter 4 we build on earlier research by Bird (1995) and more particularly by Ghosh et al. (2007). We confirm the episodic and volatile nature of non-concessional lending. We go on to calculate a series of bivariate correlations between various measures of IMF lending and the variables that theory suggests could be relevant, but find no simple and stable relationships. Finally we undertake a multivariate regression analysis aimed at explaining aggregate IMF lending using new IMF lending in a given year as our dependent variable. 
We discover that while the bivariate correlations exhibit considerable instability, these seem to mask some apparently stable and significant relationships. Global economic growth is found to have a significant and lagged negative association with new IMF lending. Real international interest rates are positively (though weakly) associated with IMF lending. Finally, and in the period 1990-2007, we find that an increase in short term debt increases the following year's level of IMF lending. However, our regression results suggest that the relationships between IMF lending and other variables (international reserves, long term debt and current account deficits) are not significant.

The predictive power of our underlying econometric model is only modest, identifying the big increase in IMF lending in 2002, as well as the jump in lending in 1990, but failing to anticipate the large increases in 1993, 1995 and 1998.

While it seems possible to isolate a number of factors that exert a significant influence over aggregate IMF lending, there is substantial evidence that the relationships identified are unstable over time in ways that are difficult to predict. This volatility makes it hard to anticipate the adequacy of the IMF's lending capacity and suggests that it is important to have institutional mechanisms that allow this capacity to be altered relatively quickly as circumstances require.

Aggregate IMF lending is of course nothing more than the sum of lending to individual countries. It is therefore important to understand the distribution of IMF lending across countries. What factors determine whether or not individual countries participate in IMF programs?

In Chapter 5 we begin by reviewing the large literature that exists on participation. We then go on to make our own estimations of an econometric model that attempts to incorporate all the variables that theory and previous studies suggest may be significant.

Countries may be expected to consider turning to the Fund when their balance of payments has become unsustainable. The reasons for this external unsustainability are likely to differ between countries. For example, low-income countries may be vulnerable to current account shocks whereas emerging economies may be more vulnerable to shocks emanating from the capital account. In both cases domestic economic mismanagement may also be an important factor although the precise nature of the mismanagement is unlikely to be identical across all countries. The underlying economic problems that countries encounter may sometimes be deep-seated and difficult to correct in the short to medium term, or they may be temporary and self-correcting. It is therefore to be expected that some countries will have a long-lasting relationship with the IMF while others may participate in IMF programs only infrequently and for shorter periods of time (Bird, 2004). 
Faced with an unsustainable balance of payments various responses may be possible, and some governments may be more inclined than others to seek IMF assistance. In determining whether or not to turn to the Fund domestic politics seem likely to play a role. As a consequence, countries that have similar economic characteristics may make different decisions with regards to borrowing from the IMF. Once the decision has been made to refer to the IMF, based on a contingent combination of the demand side economic and political factors discussed above, the IMF will have to determine its response. An important question is the extent to which this response is influenced by political factors. It seems reasonable to assume that politics will play a significant role on the supply side of participation in IMF programs as well as on the demand side. There is little doubt that the US and other wealthy (particularly European) economies are able to exert considerable influence within the IMF and will be motivated to try and use this to further their own political and commercial interests.

Chapter 5 offers a comprehensive attempt to test empirically all the potential economic and political influences on IMF participation. Our results emphasize the need for a disaggregated approach. We discover significant differences between concessional and non-concessional programs, as well as between regions and over time. While we find evidence that political factors are significant in some cases, our general conclusion is to counsel caution in assuming that US or advanced country influence provides a dominant explanation of participation in IMF programs. In many of our estimations previous programs with the IMF remains the best single predictor of current programs. No one model of participation fits all cases. While a general test of goodness of fit may seem to imply that there is much about participation in IMF programs that we are unable to explain, our analysis of false positives and negatives in Chapter 5 suggests that a substantial proportion of this is to do with the precise timing of programs.

\subsubsection{The Implementation of IMF Programs}

Having reached and signed an agreement with the IMF there is then the issue of whether the program is actually implemented. What factors affect implementation? We deal with this issue in Chapter 6 (previously published as Arpac, Bird and Mandilaras, 2008).

To begin with there is the not inconsequential problem of measuring implementation. There is no single way of doing this. One approach examines the extent to which loans are disbursed. A second examines whether programs are irreversibly interrupted. The third refers to the Fund's assessment of implementation according to its monitoring of arrangements as captured by its MONA database. There are deficiencies associated 
with each of these measures. For example, a low level of disbursement may reflect an improvement in economic performance. Meanwhile, the MONA database only covers programs coming up for review by the Fund's Executive Board, and thereby excludes cancelled or interrupted programs. Excluded programs are likely to exhibit poor implementation, and, therefore, the MONA index overstates implementation. Although the first two measures are quite closely correlated, the third is not closely correlated with the other two.

In Chapter 6 we adopt irreversible interruption as our measure of implementation. We then draw on underlying theory in order to guide our empirical estimation. This in part focuses on the marginal benefits and costs of implementation (see Bird, 2007).

The benefits arising from an IMF agreement are largely associated with the additional resources coming either directly from the IMF or indirectly via any catalytic effect that IMF programs have on other financial flows (we discuss this later). The costs are associated with the economic and political sacrifices related to implementation as perceived by the authorities. Both the benefits and the costs may turn out to be different from those that were envisaged at the time that the program was agreed, such that the political economy of implementation may differ from that of participation.

Other theoretical work has emphasized the importance of special interest groups (SIGs) that are opposed to the economic reforms embedded in programs (see, for example, Drazen, 2002; Khan and Sharma, 2008; and Mayer and Mourmouras, 2004). The more powerful these opposition groups are, the less likely it becomes that the authorities will be able to fully implement the program. These approaches are related since, with more external financing, the authorities may be in a stronger position to compensate those opposed to reform. On this basis, implementation may be expected to vary positively with the amount of financing and negatively with the strength of SIGs opposed to reform. In addition, the degree of implementation may in theory depend on the size of the problems that need to be corrected, and the incidence of shocks that blow a program off course.

Chapter 6 goes on to review the available literature before offering additional estimations testing the significance of a range of economic and political variables that theory and the extant literature identifies. Our results suggest that trade openness, the number of veto players and the amount of resources committed by the Fund are significant determinants of implementation, with the other variables being insignificant. Our overall conclusion is that the implementation of IMF programs will not be understood by examining economic factors on their own. Political influences are important, but they may have country specific elements that are missed by any one basic model. A full understanding of the implementation of IMF 
programs requires that large sample studies are augmented by structured case studies. Some of these are investigated briefly in Chapter 6. A more detailed analysis of Turkey's dealings with the IMF may be found in Arpac and Bird (2009). Since the IMF is concerned not only about the technical design of programs but will also be anxious to improve the record of implementation, the message would seem to be that it should pay close attention to the political environment in which governments seek to deliver on the commitments they make.

\subsubsection{The Effects of IMF Programs}

\section{Macroeconomic effects}

In debating the role of the IMF it is clearly important to know what impact IMF programs have on the countries that use IMF resources. A large part of the literature on the IMF has historically focused on the conditionality embodied in IMF programs and the effects of programs on various indicators of economic policy and macroeconomic outcomes (for an example of the early work on conditionality, see Williamson, 1982). In the early studies no distinction was made between programs that were implemented and those that were not, so that the effect of implementation was not evaluated. Nor was an attempt made to distinguish the effects of conditionality from those that were a consequence of the additional resources provided by IMF programs. The literature on IMF conditionality has been surveyed by Bird (2007), Dreher (2009), and Stone (2008).

Underlying all evaluation studies are fundamental methodological problems in isolating the impact of the Fund as opposed to other factors. There is no ideal way of doing this. Various approaches have been used including 'before and after' comparisons, 'with and without' comparisons, and 'performance versus target' comparisons. However, things other than IMF involvement change over time. Countries will differ in ways apart from their involvement with the Fund. In the case of performance versus target comparisons, targets may have been set unrealistically (Bird, 2005). A range of econometric and simulation techniques have also been used in an attempt to overcome the problem of estimating a counterfactual and dealing with selection bias. These methods have included the Generalised Evaluation Estimator (GEE) developed by Goldstein and Montiel (1986), Heckman two stage filters, instrumental variables (IV), and propensity score matching. None of these techniques is entirely satisfactory (see, for example, Atoyan and Conway, 2006). The GEE approach requires reliable policy reaction functions to be specified in order to calculate the counterfactual. The Heckman procedure relies on being able to find variables that appear in a selection equation but not in the structural model, and, in 
similar vein, the IV approach requires good instruments; variables that are strongly correlated with the likelihood of having a program but not with the macroeconomic outcome that is being investigated. The propensity score matching approach sets out to estimate a reasonably well-fitting participation model and to find program and non-program countries with similar propensity scores.

Evaluation is made yet more difficult by the fact that the design of conditionality has itself changed over time (see, for example, Bird, 2009, for a description and analysis of these changes). It started in the 1950s as being relatively parsimonious and involving a limited number of reasonably conventional macroeconomic policies as 'performance criteria' or 'prior actions'. Until the beginning of the 1980s IMF conditionality tended to be characterized as involving tight fiscal and monetary policy and exchange rate adjustment. In the 1980s and 1990s it became much more wide-ranging and began to incorporate a relatively large number of structural conditions in addition to the more conventional macroeconomic ones. This proliferation of conditions may have reflected an increasing consensus within orthodox economics at the time which prioritized policies of economic liberalization. However, concerns that conditionality was becoming excessive, and that this excess undermined ownership and implementation, led to a rethink. Bird (2001a) raised the possibility that there could be a conditionality Laffer curve; beyond some point the beneficial effects of conditionality might decline as the amount of conditionality rose. At the beginning of the 2000s, and perhaps reflecting an implicit acknowledgment of this view, the Fund embarked on an initiative based on 'streamlining' conditionality. This streamlining was intended to provide a clearer focus built on the institution's traditional competences and to foster stronger 'ownership' by the country's government as a means of improving implementation.

In the aftermath of the global financial and economic crisis at the end of the 2000s, the Fund undertook a major overhaul and modernization of conditionality. This reform, in part, involved redesigning its lending facilities. The use of structural conditions as performance criteria (where implementation had exhibited a particularly poor record) was discontinued. Ever since the Fund's involvement with countries as part of the East Asian crisis there had also been concerns that the strictures of conditionality were dissuading countries from borrowing from the IMF, as they preferred instead to accumulate a larger stock of their own reserves as a form of selfinsurance. Bird and Mandilaras (2011) provided some empirical justification for these concerns. To the extent that it was the case, it implied that the benefits of reserve pooling were being lost. It also implied that the perceived costs of conditionality might induce countries to try and run balance of payments surpluses in a way that would add to global economic imbalances. 
The mixed findings of evaluative studies relating to the macroeconomic effects of IMF programs on the balance of payments, inflation and growth, as well as on income distribution and poverty, have allowed commentators to draw opposing conclusions, particularly when the evidence has been used partially and selectively. Thus, ul Haque and Khan (1998) claimed that on balance conditionality worked, while the Meltzer Report (Meltzer, 2000) claimed that it did not. Bird (2001b) attempted to explain why such disparities existed with regards to the key macroeconomic variables, while Garuda (2000) showed why reaching conclusions about the distributional effects of IMF programs is far from straightforward.

We do not explore all of the issues associated with the impact of IMF programs and IMF conditionality in detail in this book. To cover the topic adequately would probably require a book in its own right. Fortunately much of the literature has been reviewed extensively elsewhere (Bird, 2007; Dreher, 2009). Instead, and more narrowly, Chapter 7 focuses on the effects of IMF programs on economic growth. As noted earlier, the Fund's Articles of Agreement state that one of the central purposes of the IMF is to facilitate economic adjustment in member countries without them having to resort to measures that are destructive of national prosperity. Testing the effect of IMF programs on economic growth enables us to assess how well this objective is being fulfilled. Moreover, sustained economic growth seems to be a reasonably reliable passport toward graduation away from the need for IMF programs. A negative effect on economic growth would therefore have the effect of making it more probable that countries would have to return to the IMF at a later date.

Chapter 7 draws on the earlier analysis of participation reported in Chapter 5 that allows us to identify countries with broadly similar propensities to participate in IMF programs. By using this empirical approach to distinguish between countries that did and did not have programs, we are able to address some of the more serious problems that arise from the selection problem mentioned earlier.

While a number of studies have been published that examine the effects of IMF programs on economic growth, we try and add value by using participation equations that better fit individual groups of countries, and in particular we discriminate between middle-income and low-income countries. We also distinguish between the effects of concessional and non-concessional programs and allow for other contingent factors including the size of programs and the degree of implementation. As with many other aspects of the IMF's operations we discover rather nuanced results. However we do find that claims that IMF programs have been universally detrimental to economic growth are not supported by the evidence. Indeed, in the case of low-income countries our evidence shows a positive effect. 
The claim that IMF programs always involve severe austerity misrepresents the reality. In discussions about the reform of IMF programs it is therefore unwise to make this assumption.

\subsubsection{Effects on Other Lending: The Catalytic Effect of IMF Programs}

For many years the IMF has claimed that one of the most important effects of its programs is to provide a 'seal of approval' that encourages other capital markets to lend more than they otherwise would have done; the so-called catalytic effect of IMF programs. In one of its 'fact files' the IMF states that programs 'can help unlock other financing, acting as a catalyst for other lenders. . . programs serve as a signal that a country has adopted sound policies. . and this increases investor confidence.' Thus, the Fund argues that catalysis operates via conditionality (Dhonte, 1997; Mussa and Savastano, 2000). More recently Morris and Shin (2006), and Corsetti et al. (2003) have developed theories of catalytic finance and have argued that IMF programs encourage others to lend by alleviating liquidity shortages.

There is an increasing amount of research that explores both the theory underpinning the catalytic effect and the empirical evidence relating to it. Cottarelli and Giannini (2002) summarize the channels through which catalysis may work and also survey the early empirical literature. The theory underpinning catalysis emerges as ambiguous (see, for example, Bird and Rowlands, 1997). An increase in interest rates and depreciation in the exchange rate may act to stimulate capital inflows, but such policies may alternatively lead to expectations of future financial problems and further depreciation and therefore have a negative effect. The potentially beneficial effects of conditionality may also be undermined by a lack of credibility associated with poor implementation.

A problem in investigating the catalytic effect is that international capital movements are themselves not fully understood and different types of capital flow are likely to be affected by different things; it is therefore difficult to be confident about the impact of Fund programs. Certainly it seems reasonable to assume that capital markets may be as likely to see IMF involvement as an indicator of current economic weakness as much as one of future strength.

The empirical evidence on the catalytic effect of IMF programs has expanded since early studies in the mid- to late-1990s. The results are mixed (see, for example, Rowlands, 2001; Bird and Rowlands, 2002; Edwards, 2006; Eichengreen et al., 2006; and Mody and Saravia, 2006). In Chapter 8 we attempt to provide a comprehensive analysis of the catalytic effect both from a theoretical and empirical perspective, whilst also 
providing a succinct summary of the existing literature. We disaggregate between different types of international capital, different IMF facilities, different time periods, different records relating to previous IMF programs and implementation, and the amount of IMF financing. We also try to distinguish between the effects of conditionality and financing. Furthermore, we allow for the possibility that the relationship between IMF programs and other flows may not be linear and may depend on the seriousness of the economic problems that bring countries to the Fund in the first place.

Our econometric investigations reported in Chapter 8 show that the sign and size of the catalytic effect varies depending on the details of the sample. This observation helps to explain why different studies that examine only a specific and narrow sample report different results. However, our general conclusion is that the catalytic effect is more often likely to be negative than it is to be positive. IMF programs may bring with them a net additional inflow of external finance but some of the IMF resources substitute for other forms of capital.

In work that is related to that reported in Chapter 8 (Bird and Rowlands, 2007a, 2009), we have distinguished between private capital flows and foreign aid. IMF programs do seem to be positively associated with additional inflows of aid for poor countries. But this may not be because of a catalytic effect in the conventional sense but more a reflection of a coordinated approach between aid donors and the IMF, with aid and IMF programs being essentially joint products. Similar findings concerning the relationship between IMF programs and foreign aid have been reported more recently by Bal Gunduz and Crystallin (2014).

There are important policy conclusions that lead on from the research on the catalytic effect. IMF programs that are under-resourced are unlikely to be successful (Bird and Rowlands, 2004). Shortages of finance will force countries to place greater reliance on faster acting adjustment policies that are difficult to implement for both economic and political reasons, and this emphasis on adjustment is likely to impair their success. There are, in turn, implications for the lending capacity of the IMF. For low-income countries the idea that aid agencies delegate the responsibility for designing and overseeing macroeconomic policy to the IMF may mean that the Fund is more important as a facilitator than as a financier in this group of countries. However, it may also have an important role to play in providing short term financing designed to protect development from the impact of temporary shocks to which LICs are vulnerable, such as the global economic crisis at the end of the first decade of the 2000s. 


\subsection{CONCLUDING REMARKS}

In terms of international monetary relations, the IMF is the most significant and pivotal international financial institution. It has therefore received a great deal of attention both in the media and amongst academics. To understand its role and operations, and to facilitate serious policy discussion, it is important to have a sound basis of research that has firm empirical foundations.

Undertaking research into the IMF presents a daunting challenge since both economics and politics are involved. There are also important legal dimensions to the Fund's activities that need to be borne in mind. Similarly, a range of complementary research methodologies may be adopted, incorporating quantitative analysis using large sample regression techniques and qualitative ones using case studies and interviews. These methods can be connected in various ways. For example, regression analysis may be used to identify outliers that can then be examined in more detail to see why they deviate from a general pattern. Case studies can add flesh to the bones of large sample results.

Although the IMF has potentially important systemic and multilateral functions in terms of overseeing international monetary arrangements, for example in encouraging international adjustment to maintain global economic imbalances at sustainable levels and regulating the amount of international liquidity, we do not directly deal with these issues in this book. Instead we focus on the stages in what we have elsewhere referred to as the 'life cycle' of IMF programs (Bird and Rowlands, 2003). The book uses large sample regression techniques to empirically examine the determinants of participation in IMF programs, their implementation, and their effects on economic growth and capital flows. However, we do augment this quantitative approach with additional qualitative analysis.

If any one simple overall conclusion emerges from the chapters that follow, it is that it is misguided to provide simple overall conclusions. The analysis and empirical results that we present provide a warning against accepting sweeping generalizations about the IMF. While it may be more exciting to find straightforward and unambiguous answers to important questions concerning the IMF, it is also important to understand why unambiguous answers are misplaced and to be aware of the complexities involved. Our hope in writing this book is that it helps to identify the complexities and therefore to provide a better foundation for understanding and then reforming the IMF. 


\section{REFERENCES}

Arpac, O. and Bird, G. (2009). Turkey and the IMF: A case study in the political economy of policy implementation. Review of International Organizations, 4(2), $135-157$.

Atoyan, R. and Conway, P. (2006). Evaluating the impact of IMF programs: A comparison of matching and instrumental variable estimators. Review of International Organizations, 1(2), 99-124.

Bal Gunduz and Crystallin, M. (2014). Do IMF supported programs catalyze donor assistance to low income countries. IMF Working Paper, WP/14/202. Washington, DC: International Monetary Fund.

Bird, G. (1999). Crisis averter, crisis lender, crisis manager: The IMF in search of a systemic role. The World Economy, 22, 955-975.

Bird, G. (2001a). IMF programmes: Is there a conditionality Laffer curve? World Economics, 2(2), 29-49.

Bird, G. (2001b). IMF programs: Do they work? Can they be made to work better? World Development, 29, 1849-1865.

Bird, G. (2003). Restructuring the IMF's lending facilities. The World Economy, 26(2), 229-245.

Bird, G. (2004). The IMF forever: An analysis of the prolonged use of fund resources. Journal of Development Studies, 40(6), 30-58.

Bird, G. (2005). Over-optimism and the IMF. The World Economy, 28, 1355-1373.

Bird, G. (2007). The IMF: A bird's eye view of its role and operations. Journal of Economic Surveys, 21(4), 683-745.

Bird, G. (2009). Reforming IMF conditionality: from streamlining to major overhaul. World Economics, 10(3), 81-104.

Bird, G. and Mandilaras, A. (2011). Once bitten: The effects of IMF programs on subsequent reserve behavior. Review of Development Economics, 15(2), 264-278.

Bird, G. and Rowlands, D. (1997). The catalytic effect of lending by the international financial institutions. The World Economy, 20(7), 967-991.

Bird, G. and Rowlands, D. (2002). Do IMF programmes have a catalytic effect on other international capital flows? Oxford Development Studies, 30, 229-249.

Bird, G. and Rowlands, D. (2003). Political economy influences within the life cycle of IMF programmes. The World Economy, 26(9), 1255-1278.

Bird, G. and Rowlands, D. (2004). Financing balance of payments adjustment: Options in the light of the elusive catalytic effect. Comparative Economic Studies, 46, 468-486.

Bird, G. and Rowlands, D. (2006). IMF quotas: Constructing an international organisation using inferior building blocks. Review of International Organizations, 1, 153-171 (Reprinted as Chapter 2, this volume).

Bird, G. and Rowlands, D. (2007a). The IMF and the mobilisation of foreign aid. Journal of Development Studies, 43(5), 856-870.

Bird, G. and Rowlands, D. (2007b). Should it be curtains for some of the IMF's lending windows? Review of International Organizations, 2(3), 281-299 (Reprinted as Chapter 3, this volume).

Bird, G. and Rowlands, D. (2009). Financier or facilitator: The changing role of the IMF in low income countries, in J. Boughton and D. Lombardi (eds), Finance, Development and the IMF: Chapter 6. Oxford: Oxford University Press. 
Bird, G. and Rowlands, D. (2010). The episodic and unpredictable nature of IMF lending: An empirical analysis. The World Economy, 33(10), 1280-1301.

Bird, G. and Willett, T.D. (2007). Multilateral surveillance: Is the IMF shooting for the stars? World Economics, 8(4), 167-189.

Corsetti, G., Guimaraes, B., and Roubini, N. (2003). International lending of last resort and moral hazard: A model of IMF catalytic finance. NBER Working Paper 10125.

Cottarelli, C., and Giannini, C. (2002). Bedfellows, hostages or perfect strangers? Global capital markets and the catalytic effect of IMF crisis lending. IMF Working Paper 02/193. Washington, DC: IMF.

Drazen, A. (2001). Conditionality and ownership in IMF lending: A political economy approach. IMF Staff Papers, 49 (special issue), 36-67.

Dhonte, P. (1997). Conditionality as an instrument of borrower credibility. Papers on Policy Analysis and Assessment 97/2, Washington, DC: International Monetary Fund.

Dreher, A. (2009). IMF conditionality: Theory and evidence. Public Choice, 141, 233-267.

Edwards, M.S. (2006). Signalling credibility? The IMF and catalytic finance. Journal of International Relations and Development, 9, 27-52.

Eichengreen, B., Kletzer, K. and Mody, A. (2006). The IMF in a world of private capital markets, Journal of Banking and Finance, 30, 1334-57.

Ghosh, A., Goretti, M., Joshi, B., Thomas, A., and Zalduendo, J. (2007). Modeling aggregate use of fund resources: Analytical approaches and medium-term projections. IMF Working Paper, WP/07/70.

Khan, M. and Sharma, S. (2008). IMF conditionality and country ownership of programs. IMF Working Paper, 01/142.

Mayer, W. and Mourmouras, A. (2004). IMF conditionality and the theory of special interest politics. Comparative Economic Studies, 46, 400-422.

Meltzer, A.H. (2000). International Financial Institution Advisory Commission. Washington, DC: United States House of Representatives.

Mody, A., and Saravia, D. (2006). Catalyzing capital flows: Do IMF-supported programs work as commitment devices? Economic Journal, 116(513), 843-867.

Morris, S., and Shin, H.S. (2006). Catalytic finance: When does it work? Journal of International Economics, 70, 161-177. Mussa, M. and Savastano, M. (2000). The IMF approach to economic stabilization, in B.S. Bernanke and J.J. Rotemberg (eds), NBER Macroeconomics Annual 1999: 79-122. Cambridge, MA: MIT Press.

Rowlands, D. (2001). The response of other lenders to the IMF. Review of International Economics, 9, 531-546.

Stone, R.W. (2008). The scope of IMF conditionality. International Organization, 62, 589-620.

Stiglitz, J. (2002). Globalization and Its Discontents. New York: W.W. Norton.

ul Haque, N.U. and Khan, M.S. (1998). Do IMF-supported programs work? A survey of the cross-country empirical evidence. IMF Working Paper, 98/169.

Williamson, J. (ed.) (1982). IMF Conditionality. Cambridge, MA: MIT Press. 